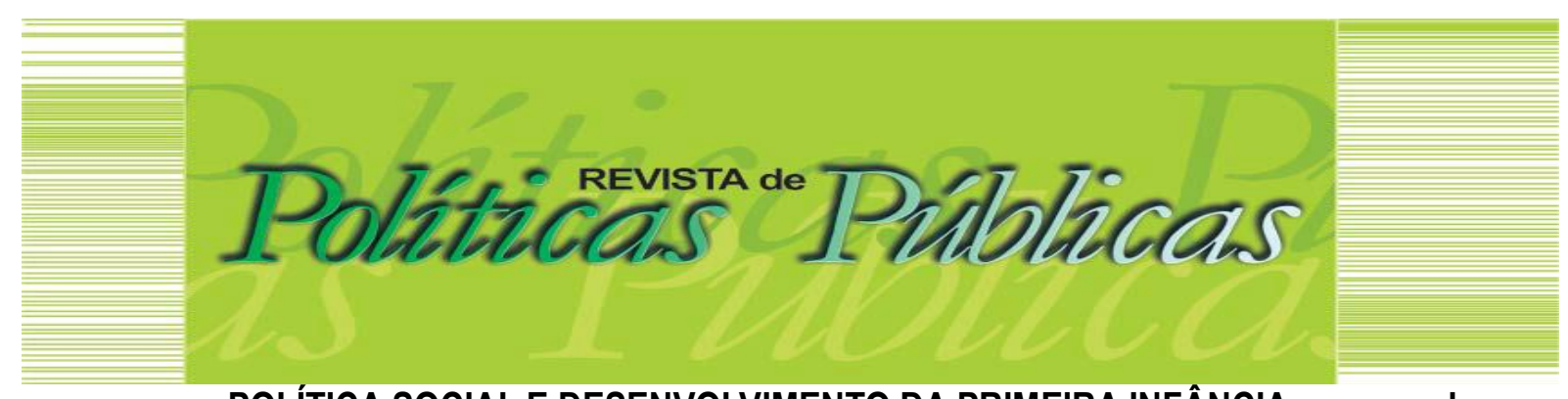

\title{
POLITICA SOCIAL E DESENVOLVIMENTO DA PRIMEIRA INFÂNCIA: mapeando condições no Espírito Santo, 2012 a 2017
}

Rodrigo Emmanuel Santana Borges ${ }^{1}$ Maria Lúcia Teixeira Garcia² Arelys Esquenazi Borrego 3 Aline Faé Stocco 4 Aline Elisa M. Lang ${ }^{5}$

\section{Resumo}

O artigo aborda a primeira infância no estado do Espírito Santo, identificando, entre 2012 e 2017, avanços e retrocessos nas políticas de educação, assistência e saúde dessa área. Para tanto, criou um banco de dados municipal a partir de microdados majoritariamente censitários dos Ministérios da Saúde e da Educação, assim como da Secretaria Especial do Desenvolvimento Social. A partir desses dados, ligados a crianças de 0 a 6 anos, faz uma análise das variáveis como taxa de cobertura escolar, cobertura do Programa Bolsa Família, indicadores de mortalidade infantil e materna, fecundidade e atenção à gestante. A base compilada disponível permite a elaboração de estudos regionais desagregados e no tempo. Por serem dados completos da população, a análise panorâmica pode ser baseada em uma análise de estatística descritiva. Comprova, assim, avanço no atendimento à primeira infância, em paralelo à vigência continuada de disparidades regionais importantes.

Palavras-chave: Política social. Primeira Infância. Espírito, Santo, Brasil.

\section{SOCIAL POLICY AND EARLY CHILDHOOD DEVELOPMENT: Mapping conditions in Espírito Santo, Brazil from 2012} to 2017

\section{Abstract}

The paper carries out a mapping of the public conditions of early childhood care in the state of Espirito Santo, Brazil, for the period between 2012 and 2017. To this end, it created a municipal database using mostly census microdata from the Ministries of Health and Education, as well as the Special Secretariat for Social Development. Based on these data, linked to children from 0 to 6 years old, it makes an analysis of variables such as school coverage rate, coverage of the Bolsa Família Program, indicators of infant and maternal mortality, fertility and attention to pregnant women. The available compiled base allows for the development of regional, disaggregated and time studies. As they are complete population data, the panoramic analysis can be based on a descriptive statistical analysis. Thus, it proves progress in early childhood care, in parallel with the continued existence of important regional disparities.

Keywords: Social Policy. Early Childhood Development. Brazil. Espírito Santo.

Artigo recebido em: 10/04/2020 Aprovado em: 13/10/2020 DOl: http://dx.doi.org/10.18764/2178-2865.v24n2p858-877.

\footnotetext{
1 Economista. Doutor em Economia Internacional e Desenvolvimento pela Universidad Complutense de Madrid. Bolsista de pós-doutorado (EDITAL FAPES/CAPES N. 10/2018 - PROFIX 2018) no Programa de Pós-Graduação em Política Social (PPGPS) da UFES. E-mail: rodrigo@borges.net.br. ORCiD: 0000-0003-2076-1424.

2 Assistente Social. Doutora em Psicologia Social pela Universidade de São Paulo (USP/2001). Professora titular do Departamento de Serviço Social e do Programa de Pós- Graduação em Política Social da Universidade Federal do Espírito Santo (UFES). E-mail: lucia-garcia@uol.com.br. ORCID: 0000-0003-2672-9310.

${ }^{3}$ Economista. Mestre em Economia pela Universidad de la Habana (UH). Doutoranda do Programa de Pós-graduação em Política Social (PPGPS) da Universidade Federal do Espírito Santo (UFES). Bolsista CAPES. E-mail: arelyseb@gmail.com. ORCID: 0000-0002-9366-8688.

${ }^{4}$ Economista. Doutora em Política Social pela Universidade Federal do Espírito Santo (UFES). Professora-adjunta da Universidade Federal dos Vales do Jequitinhonha e Mucuri (UFVJM). E-mail: aline.stocco@ufvim.edu.br. ORCID: 00000001-8817-9313.

${ }^{5}$ Assistente Social. Mestre em Política Social pela Universidade Federal do Espírito Santo (UFES). Atualmente doutoranda do Programa de Pós-graduação em Política Social da UFES. Bolsista FAPES. E-mail: alinelisa lang@hotmail.com. ORCID: 0000-0002-5022-5692.
} 


\section{INTRODUÇÃO}

A primeira infância tornou-se tema de crescente destaque nas agendas governamentais. Além da ênfase em eventos internacionais, foi incluída de maneira direta e/ou indireta em pactos como os apresentados nos Objetivos de Desenvolvimento do Milênio (2000) e nos Objetivos de Desenvolvimento Sustentável (2014) (FUJIMOTO, 2016). Tendo-a como alvo, significativas mudanças nas leis e regulações relacionadas às políticas públicas foram sugeridas e implementadas. Ainda que apresentadas como resultado dos avanços alcançados pelas pesquisas científicas sobre 0 desenvolvimento humano, na medida em que apontam os primeiros anos de vida das crianças como uma etapa estratégica para a formação e para o desenvolvimento de habilidades e capacidades que são determinantes para o desempenho futuro, peculiarmente, elas se encaixam na ideologia neoliberal. Nesse sentido, a primeira infância aparece como um período estratégico para a realização de investimentos em políticas públicas direcionados à promoção de justiça e de equidade social (FUJIMOTO, 2016).

A focalização das políticas sociais na primeira infância está inscrita, na realidade, no movimento mais amplo de reconfiguração dos sistemas de proteção social iniciado nos anos de 1980. Partindo de um diagnóstico de desestabilização das economias industriais tradicionais e da constituição de um novo contexto econômico marcado por maior concorrência e pela economia da informação, os sistemas de proteção social foram considerados desajustados, contraproducentes e insustentáveis pelo discurso ortodoxo. Ao desenvolver essa linha argumentativa, Esping-Andersen e Palier (2010) defenderam, então, a substituição das políticas sociais consideradas reparadoras e compensatórias por uma estratégia preventiva, focalizada nas mulheres e crianças. Para Adelantado (2017, p. 48), o novo paradigma da proteção social se pauta por dotar os cidadãos de capacidade para que protejam a si mesmos frente aos mercados, tornando-se individualmente responsáveis frente aos riscos sociais das sociedades "pós-industriais".

No Brasil, os cuidados com a primeira infância também têm recebido atenção crescente. Exemplos disso são vários programas e ações de políticas públicas, e, inclusive, a criação de um marco legal para as políticas de primeira infância (Lei $n^{0}$. 13.257), de março de 2016. A aprovação desse instrumento é parte, também, de uma trajetória histórica de criação e implementação de programas e ações desenvolvidos no país com foco no reconhecimento e na proteção dos direitos da criança e do adolescente, em que se destacam o artigo 227 da Constituição Federal de 1988, assim como o Estatuto da Criança e do Adolescente, instituído em julho de 1990 e que deu origem ao Sistema de Garantia de Direitos composto por conselhos, promotorias, defensorias, varas de infância, 
delegacias e um conjunto de serviços de assistência e atendimento à criança e ao adolescente (FUJIMOTO, 2016; IJSN, 2016).

O fosso que separa as garantias estabelecidas na legislação brasileira e os resultados entregues no âmbito das políticas públicas é, porém, enorme. 0 ambiente urbano e o rural em que as crianças brasileiras crescem é caracterizado por uma conjunção de fatores de risco (violência, falta de saneamento básico, pobreza) que, somados a serviços de educação e saúde insuficientes e com variados níveis de qualidade, configuram vulnerabilidades ameaçadoras às potencialidades e oportunidades presentes nessa etapa do ciclo de vida humano (CECCON, 2016).

Assim, o presente artigo tem por objetivo oferecer um panorama, o mais completo e preciso possível, sobre a atenção à primeira infância no estado brasileiro do Espírito Santo (ES), em uma perspectiva de identificar avanços e retrocessos ocorridos em termos de política social nas áreas de educação, assistência e saúde, entre os anos de 2012 e 2017, assim como evidenciar a forma de reprodução da desigualdade territorial característica na história dessa unidade federativa. $O$ estado do ES se apresenta como um microcosmo privilegiado, como síntese da desigualdade macrorregional brasileira.

O artigo está dividido em cinco seções além dessa introdução. Na próxima seção, empreende-se contextualização histórica referente ao desenvolvimento econômico e social do ES, evidenciando suas particularidades. Na seção subsequente, são apresentados elementos específicos da realidade contemporânea da primeira infância no estado. Em seguida, indica-se a metodologia utilizada para a coleta dos dados. Já na quinta seção, procede-se à análise dos dados coletados na pesquisa. Por fim, realiza-se a síntese das principais descobertas do estudo, com considerações finais que apontam perspectivas para novas pesquisas sobre a temática.

\section{O DESENVOLVIMENTO DO ESPÍRITO SANTO E AS POLÍTICAS DE PRIMEIRA INFÂNCIA}

Entre os estados da Região Sudeste, que possuem maior concentração populacional e produtiva no território nacional, o ES se diferencia por apresentar um desenvolvimento urbano e industrial atrasado, em parte decorrente do processo de colonização, quando, durante o auge da atividade de mineração aurífera em Minas Gerais, foi mantido isolado e teve sua ocupação desestimulada (ROCHA; MORANDI, 2012).

Segundo Oliveira (2008), até a metade do século passado, o ES era um estado essencialmente agrícola. 0 café, principal produto e fonte de arrecadação, era a base articuladora de todo o comércio e da indústria nele nascentes. Foi precisamente com base na cultura cafeeira que a região se integrou ao comércio internacional e vivenciou todas as crises econômicas, sofrendo seus 
intensos impactos. Não obstante, a mesma base agrária que possibilitou sua inserção no mercado internacional, também foi identificada como responsável pelo relativo atraso do estado, como refletido, por exemplo, pela baixa qualidade do café ali produzido até bem próximo do final do século XX.

Em relação à economia cafeeira, a região sul do ES apresentou maior protagonismo na produção, desenvolveu uma estrutura produtiva e uma forma de inserção na economia nacional e no comércio internacional que se contrastou com a região norte, caracterizada por maiores vazios territoriais (GARCIA; GARCIA, 1997). Além disso, como resultado da relevância adquirida pela monoprodução do café, a maior concentração demográfica também se produziu no sul, sobretudo no extremo sudoeste e na região de Vitória. Já ao norte do Rio Doce, o povoamento demorou a assumir características de "ocupação permanente". Historicamente, o território foi caracterizado por grandes áreas de terras devolutas e uma economia de caráter extrativo.

Na segunda metade da década de 1950, a queda registrada nos preços do café repercutiu de modo significativo na economia capixaba, ao desatar uma crise econômica e social (DARÉ, 2010; BITTENCOURT, 1987). Em decorrência desse contexto de "crise do café" e sob influência da proposta desenvolvimentista do país, a estratégia econômica que se verificou foi de diversificação da estrutura produtiva: o fomento de uma produção de café de elevada qualidade e, paralelamente, 0 desenvolvimento de uma base urbana e industrial baseada na produção de produtos primários exportáveis (OLIVEIRA, 2008). Entre os projetos industriais desenvolvidos nesses anos, além da Companhia Vale do Rio Doce (CVRD), destacam-se também a implantação do Centro Industrial de Vitória (CIVIT), o complexo da Companhia Siderúrgica de Tubarão (CST), entre outros polos industriais.

Segundo Bittencourt (1987), os anos de 1970 também foram marcados por uma forte migração para a Grande Vitória, o que, na ausência de infraestrutura urbana adequada, intensificou 0 surgimento de favelas e áreas periféricas. Se, nos anos 1960, 70,8\% da população residia na zona rural, em 1980, apenas 36\% permaneciam lá. Assim, o ES, nos anos 1970-1980, passou por um intenso processo de urbanização concentrado na região da Grande Vitória e alguns poucos municípios vizinhos (GARCIA; GARCIA, 1997). Nesse processo, recebeu migrantes de diversos estados, principalmente de Minas Gerais, Rio de Janeiro e Bahia, vindos como mão de obra para a indústria e para as atividades ligadas a ela, dentre as quais se destacam as obras imobiliárias.

Em relação ao processo de industrialização, cabe destacar seu caráter tardio, descontínuo e incompleto. As grandes plantas industriais instaladas não foram acompanhadas de um processo integrado e contínuo de multiplicação de investimentos na indústria de bens de capital. Por um lado, esse processo se caracterizou pela elevada especialização na produção de commodities minerais e agroindustriais (minérios, produtos siderúrgicos, produção de mármore e granito, celulose, café torrado e instantâneo etc). Por outro, marcou-se pela concentração territorial na Região Metropolitana da 
Grande Vitória. Ao mesmo tempo, esse processo também foi responsável por impactar negativamente o meio ambiente e a saúde, assim como pelo maior empobrecimento urbano na Grande Vitória (SIQUEIRA, 2001).

No entanto, na agricultura, o estado continuou primando pela expansão de monoculturas como café, eucalipto, arroz, milho e feijão, as quais colocam o ES, na atualidade, como o principal produtor de celulose e segundo maior de café no Brasil - e, logo, pelo aumento da concentração fundiária, pela perda de diversidade agrícola etc. Outro fato relevante na conformação da economia capixaba é a forma como esta se assenta no acesso ao mar, ao menos desde a segunda metade do século passado, culminando em fortes relações econômicas com o estado de Minas Gerais para 0 escoamento da produção de minérios, com grandes investimentos em ferrovias e portos (SIQUEIRA, 2009).

O esvaziamento dos grandes projetos industriais de desenvolvimento conduzidos pelo estado e o esforço empreendido para elevar o volume das exportações brasileiras na década de 1980, somado à posterior abertura comercial no contexto de implantação das políticas neoliberais no país, acabaram alterando os vetores básicos do crescimento econômico do estado a partir dos últimos anos do século passado. 0 desempenho das atividades econômicas passou à órbita do comércio exterior de mercadorias (GOMES, 2008).

Assim, um importante pilar contemporâneo da economia capixaba são as atividades de comércio exterior, fundamentalmente aquelas ligadas às atividades portuárias. Isso ocorre como resultado da localização geográfica privilegiada, dos investimentos realizados em infraestrutura nas últimas décadas e da existência de um sistema de incentivos fiscais (como, por exemplo, o Fundo de Desenvolvimento das Atividades Portuárias - FUNDAP), que transformaram o ES no estado com a estrutura produtiva mais extrovertida do país. Já na primeira década dos anos 2000 , em um contexto de valorização das commodities no mercado internacional, o estado recebeu grandes investimentos na mesma linha, relacionados à sua estrutura produtiva voltada ao comércio exterior, inclusive com o início das explorações de petróleo, pela Petrobras, nas águas do estado (MAGALHÃES; TOSCANO, 2011). $\mathrm{Na}$ atualidade, o ES é o segundo na produção de petróleo e o quarto na de gás natural do Brasil (ANP, 2019).

Por outro lado, no campo político, o estado vivenciou, nos últimos 30 anos, momentos de fortes turbulências. No início dos anos 1990, isso se plasmou no começo de uma grave crise política e institucional, em que agentes públicos e autoridades políticas e empresariais foram flagrados em diversos escândalos de corrupção e até de assassinatos ${ }^{1}$, o que terminou expondo um entranhamento do crime organizado nas estruturas do poder público estadual e no seu alto-comando. Esses fatos levaram inclusive à intervenção federal e a denúncias contra autoridades capixabas em cortes 
internacionais $^{2}$. Para Oliveira Jr. $(2013$, p. 72$)$, um dos elementos principais da crise foi 0 comportamento anacrônico de uma parte desses setores políticos que "não compreendiam mais as exigências históricas e sociais demandadas pelo processo de acumulação de capital no estado e no mundo", e, dessa maneira, não respondiam aos novos interesses econômicos dominantes no ES e às novas demandas apresentadas.

Foi nesse contexto que, em 2003, Paulo Hartung foi eleito para o comando do executivo estadual, tendo sido reeleito, em 2006, para um segundo mandato, o que abriu um ciclo de relativa estabilidade política. Ele iniciou a implantação de um novo modelo de gestão pública, inspirada pela chamada New Public Management (NPM), o que significou uma reforma gerencial e tecnocrática no aparelho do estado, seguindo o modelo da reforma implementada em âmbito federal durante o primeiro mandato do presidente Fernando Henrique Cardoso (OLIVEIRA JR. 2013). O objetivo, segundo documentos institucionais, era a construção de uma nova institucionalidade de gestão pública baseada no fortalecimento das parcerias do governo estadual com o setor empresarial, terceiro setor e organizações comunitárias (ESPÍRITO SANTO, 2006).

Com o slogan "um novo Espírito Santo" e apelos constantes quanto à necessidade de cortar gastos públicos, apresentados como uma espécie de "sacrifícios" que deveriam ser realizados pelo conjunto dos capixabas, os serviços públicos essenciais foram mantidos sob forte restrição orçamentária, enquanto o governo registrava recorrentes aumentos de receita, superavit fiscais e aumentava o volume de renúncias fiscais que privilegiavam determinados setores da economia regional (GOMES, 2015).

Em que pese a mudança na condução política do estado, no período de 2011 a 2014, com a eleição de Renato Casagrande, a tônica da austeridade como política do governo capixaba retornou ainda na disputa eleitoral de 2014, quando novamente foi eleito Paulo Hartung (OLIVEIRA; LIRIO, 2017). Ao assumir o governo, em 2015, o discurso oficialista recriou um cenário de crise que seria decorrente de um suposto desequilíbrio das contas públicas, justificando, assim, a adoção de medidas impopulares. Em realidade, o que se assistiu foi novamente cortes de investimentos e redução dos serviços públicos. Nas palavras de Oliveira e Lirio: "[...] as políticas sociais, a educação e diversas outras urgências permanecem excluídas de sua agenda, e, quando incluídas, estão submetidas aos interesses dos segmentos empresariais a que PH representa" (2017, p. 282).

Tudo isso evidencia que esse período de retomada da estabilidade política não possibilitou a recuperação da capacidade de o estado promover e executar políticas públicas direcionadas às parcelas mais empobrecidas da população para reduzir os problemas sociais que se acumularam no território capixaba, dentre os quais são destaque a desigualdade territorial e a dificuldade de acesso aos serviços públicos. 
A heterogeneidade produtiva resultante da conformação histórica brevemente esboçada é uma das causas da marcada desigualdade territorial. Esta se expressa tanto em termos econômicos quanto sociais, infraestruturais, urbanos, populacionais etc. A brecha territorial norte-sul no ES nunca foi totalmente superada, independentemente das estratégias de desenvolvimento aplicadas; inclusive, em algumas conjunturas, aquela se aprofundou por causa destas.

Mesmo com a presença de ações afirmativas nas últimas décadas, a desigualdade territorial continua sendo relevante dentro do panorama econômico e social do estado. No Plano de Desenvolvimento 2025, por exemplo, o governo aponta:

[...] para reverter a tendência de concentração excessiva da riqueza e das oportunidades no litoral - sobretudo na RMGV [...é mister desenvolver...] iniciativas integradas envolvendo os mais diversos atores sociais, econômicos e políticos, visando reforçar a dinâmica econômica do interior, apoiando-a nas vocações e especializações regionais (ESPÍRITO SANTO, 2006, p. 54).

$\mathrm{Na}$ atualização do plano de desenvolvimento, sintetizada no relatório ES2030, 0 compromisso foi reafirmado na medida em que, para a construção da visão de futuro, as prioridades seriam "a redução das desigualdades sociais e o crescimento regionalmente equilibrado" (ESPÍRITO SANTO, 2013, p. 14).

É nesse cenário que a questão da infância no ES entra no planejamento do governo. Dessa forma, em resposta à demanda das mulheres, o governo propõe o acesso das crianças à creche e à educação básica universalizada. Entretanto, essas demandas apresentam particularidades entre as regiões urbanas e rurais, além das dimensões de classe e étnico-raciais.

\section{O ESPÍRITO SANTO E A PRIMEIRA INFÂNCIA ATÉ A DÉCADA DE 2010}

As condições econômicas e sociais têm influência sobre as condições de saúde de pessoas e populações (CARVALHO, 2013). Entender a formação econômica e social do ES, assim como sua evolução histórica, é fundamental para compreendermos a dinâmica da pobreza e as mudanças econômicas e sociais que norteiam as políticas sociais voltadas para as famílias, refletindo, também, na política de atenção à infância.

De acordo com o censo de 2010, o Brasil tinha uma população total de 190.732 .694 pessoas, sendo que 3.512.672 eram habitantes do ES. Desse total, cerca de $10 \%$ das populações deste e do Brasil são crianças na primeira infância (de 0 a 6 anos) (PEREIRA; SAMPAIO, 2011). Ainda que um balanço do período entre 1988 e 2008 indique uma diminuição da pobreza e da desigualdade de renda no estado, a concentração da pobreza entre crianças é maior (BARROS et al, 2010, p. 33). Entre os anos 2001 e 2009, de acordo com o discurso oficialista, teria sido observada uma redução 
relativa do número de pobres ${ }^{3}$ no $\mathrm{ES}$, passando de 32,8\%, em 2001, para 15,0\%, em 2009 (FERRARI et al, 2011). Quanto aos extremamente pobres, teria havido uma queda de 8,4 pontos percentuais nesse mesmo período. No entanto, a pobreza incide principalmente nas crianças e adolescentes de $0 \mathrm{a}$ 15 anos e nos idosos de 60 anos ou mais. 0 maior índice de pobreza estadual ocorreria na faixa de 5 a 10 anos, "visto que, nessa idade, $32,9 \%$ das crianças seriam pobres caso não houvesse o benefício do PBF e 41,9\% seriam pobres no caso de não haver nenhum tipo de transferência" (FERRARI et al, 2011, p. 10).

No ES, assim como no Brasil, nas últimas três décadas, ao menos, alcançou-se melhora em indicadores como, por exemplo, taxas de mortalidade infantil e de crianças menores de cinco anos (BRASIL, 2010). Em 1995, no ES, a taxa de mortalidade na infância era de 5,37 óbitos por mil nascidos vivos, sendo que, em 2007, esse número caiu para 2,84 (PEREIRA; SAMPAIO, 2011). Já a taxa de mortalidade infantil caiu de 23,62 óbitos por mil nascidos vivos, em 1995, para 11,96, em 2009 - uma redução equivalente a 49,4\% entre 1995 e 2009 (PEREIRA; SAMPAIO, 2011).

As melhorias nas condições de saneamento, o aumento dos anos de estudos das mães, a melhoria do atendimento prestado à atenção básica - por meio do SUS e PSF -, assim como as ações de imunização e de vigilância sanitária e epidemiológica contribuíram para a redução da mortalidade por doenças infecciosas no total de óbitos infantis no Brasil e no ES (BRASIL, 2010). Entretanto, chamam atenção as afecções perinatais ${ }^{4}$, que aparecem como a principal causa de mortalidade de crianças menores de um ano no Brasil. Em 1990, estas correspondiam a 40\% dos óbitos. Em 2008, essa proporção subiu para 60\% (BRASIL, 2010). No ES, as afecções perinatais também apareciam como a principal causa de mortalidade de crianças menores de um ano, correspondendo a $59,4 \%$ dos óbitos infantis em 2008 (PEREIRA; SAMPAIO, 2011).

Se, por um lado, houve redução na mortalidade infantil, por outro, as quedas nas taxas de fecundidade apenas acompanharam a tendência mundial, e, particularmente, não se verificou avanço expressivo na redução da fecundidade adolescente (BRASIL, 2015).

Entre os avanços no campo da educação, o conjunto de leis ${ }^{5}$ instituídas favoreceu 0 reconhecimento da educação infantil como direito fundamental e dever do Estado, significando um aumento da escolarização de crianças na primeira infância. No entanto, as disparidades regionais e entre as faixas etárias ainda permaneceram como problemas importantes (BRASIL, 2010). De acordo com estimativas da Pnad, 53\% das crianças de 0 a 6 anos estavam fora da escola no Brasil (IBGE, 2009). No ES, o número absoluto de crianças dessa mesma faixa etária nessa condição era de 177 mil (50,9\%) (PEREIRA; SAMPAIO, 2011).

A realidade nacional apontava para uma diferença considerável no acesso à escola de acordo com a faixa etária. No ES, na faixa etária de 0 a 3 anos, o percentual de crianças que 
frequentavam a creche, em 2009, era de $20 \%$, enquanto o percentual de crianças entre 4 e 6 anos em pré-escolas se elevou para $83 \%$ do total (PEREIRA; SAMPAIO, 2011).

De acordo com dados do SIMEC/MEC, no ES, somente $26,10 \%$ das crianças de zero a três anos eram atendidas na Educação Infantil, em 2013, sendo esse um valor ligeiramente inferior ao percentual registrado na Região Sudeste $(28,3 \%)$, mas superior ao encontrado no Brasil $(23,2 \%)$. Diante desse quadro, o Diagnóstico da Educação do estado (ESPÍRITO SANTO, 2014) constatava que, para universalizar até 2016 a educação infantil na pré-escola para as crianças de 4 e 5 anos (conforme o Plano Estadual de Educação), era necessário, até 2016, aumentar a oferta em 22,2\%, bem como ampliar 0 atendimento educativo nas creches, em, no mínimo, 50\%, para as crianças de até 3 anos.

Outra mudança observada na realidade da infância capixaba, no contexto recente, foi no tocante ao trabalho infantil. Em relação à primeira infância, em 2009, havia cerca de 20 mil crianças, entre 5 e 6 anos, em situação de trabalho infantil no Brasil e cerca de 1.000, com 6 anos de idade, nessa mesma condição no ES (IBGE, 2009).

Ao apresentarmos aqui os dados médios do Brasil e do estado, não se evidenciaram as desigualdades entre as regiões, tampouco mostrou-se a evolução nos últimos 7 anos. Dessa forma, passemos a analisar os dados do ES em termos regionais e contemporâneos. Para isso, apresentamos, a seguir, a metodologia utilizada para obter os dados e, posteriormente, os resultados encontrados.

\section{A METODOLOGIA CRIADA E EMPREGADA NO ESTUDO}

Para o estudo, foram utilizados microdados oficiais, disponíveis publicamente nas seguintes fontes: Datasus (MS, 2019), IBGE (2019), Censo Escolar (INEP/MEC, 2019) e CadÚnico (SDS, 2019).

Os dados populacionais municipais por faixa etária detalhada, de 0 a 3 e de 4 a 6 anos, foram obtidos a partir de estimativas próprias, baseadas nas pirâmides etárias municipais e estadual (DATASUS/RIPSA/IBGE) - último ano disponível 2015 -, em combinação com dados de nascimentos e mortes do DATASUS, tábuas de mortalidade completas do IBGE e estimativas de população total do ES para anos posteriores a 2015. As fontes foram combinadas de maneira a mitigar a ausência de informação sobre migrações, tendo sido, dentro das possibilidades, a melhor forma encontrada para estimação desses dados.

Uma vez obtidas as estimativas detalhadas da população infante, os indicadores foram calculados por meio de tabulações específicas produzidas a partir dos microdados das fontes oficiais referidas para áreas de educação, saúde e assistência social. Os indicadores foram calculados para 0 
Brasil, para o ES e para as microrregiões estaduais, tal como definido pelo IBGE, a partir de uma base municipal construída para todos os indicadores.

$\mathrm{Na}$ área de educação, foram computados os seguintes indicadores:

a) Taxa de Cobertura Efetiva de Creche = alunos de 0 a 3 anos matriculados em creche/ total de alunos em idade de creche ( 0 a 3 anos);

b) Taxa de Cobertura Bruta de Creche $=$ total de matriculados em creche/ total de alunos em idade de creche ( 0 a 3 anos);

c) Taxa de Cobertura Efetiva e Bruta de Pré-Escola = igual ao cômputo referido à creche, mas para idade pré-escolar (4 a 6 anos);

d) Matrículas públicas em creches do total $=$ total de matriculados em creches públicas/ total de matrículas em creches;

e) Matrículas públicas em pré-escolas do total = total de matriculados em préescolas públicas / total de matrículas em pré-escolas;

f) Creches por 1.000 crianças, pré-escolas por 1.000 crianças;

g) Alunos de creche por sala, alunos de pré-escola por sala.

$\mathrm{Na}$ área de saúde, os indicadores obtidos referem-se à cobertura de assistência médica para gestantes, fecundidade adolescente, bem como mortalidade materna e infantil. Dessa forma, foram computados os seguintes dados:

a) Proporção das gestações que não tiveram nenhuma consulta de pré-natal em relação ao total;

b) Proporção das gestações com consultas pré-natais, até 6 consultas, em relação ao total;

c) Proporção de gestações com 6 ou mais consultas pré-natais em relação ao total;

d) Proporção dos nascidos com parto cesáreo em relação ao total;

e) Nascidos em hospital em proporção ao total de nascimentos;

f) Mortes relativas ao parto a cada 1.000 mulheres em idade fértil;

g) Mortes relativas ao parto a cada 1.000 partos;

h) Fecundidade adolescente, obtida a partir do número de nascidos de adolescentes até 19 anos, dividido por 1.000 mulheres adolescentes, na faixa etária entre $10 \mathrm{e}$ 19 anos.

$\mathrm{Na}$ área de assistência social, computou-se a proporção da população de primeira infância cadastrada no CadÚnico e daquela beneficiária do Programa Bolsa Família (PBF) $)^{6}$, frente à população total de 0 a 6 anos em cada município. Além disso, obteve-se o total de crianças beneficiárias deste programa por microrregião e município?. 
Uma vez que a construção de indicadores foi feita sobre a base de indicadores censitários (à exceção parcial dos dados do Cadúnico, de cuja base censitária foi acessada a amostra desidentificada, construída de forma a ser representativa do conjunto da população cadastrada), a construção dos indicadores foi, em princípio, robusta, e sua análise não exigiu, na medida em que não se buscou neste primeiro estudo relações de causalidade, testes estatísticos ou econométricos, mas apenas descrição e comparação das populações escolhidas como objeto.

\section{UM MAPA DA PROTEÇÃO À PRIMEIRA INFÂNCIA NO CONTEXTO CONTEMPORÂNEO DO ESPÍRITO SANTO}

No âmbito da educação, a análise dos dados mostra que, em 2017, a cobertura préescolar efetiva alcançada no ES se situava bem acima da média brasileira, mas alcançou menos de $60 \%$, estando longe da universalização. A discrepância regional é evidente ao compararmos, por exemplo, a microrregião de Nova Venécia, representativa da região noroeste capixaba8 ${ }^{8}$ (cobertura de $55,67 \%$, em 2017), e Itapemirim, no sul espírito-santense (que alcançou cobertura de 69,26\%). No tempo, percebe-se como a trajetória de melhora na cobertura pré-escolar se interrompeu em 2015, tanto para o Brasil como um todo como para praticamente todas as microrregiões capixabas, marcando uma estagnação nos indicadores desde então.

No tocante à efetiva cobertura de creche, no estado, houve melhoria apenas tênue nos últimos anos, sendo esta menos destacada do que a ocorrida no cenário nacional, ainda que a cobertura estadual, em 2017, tenha sido de praticamente $30 \%$ de infantes de 0 a 3 anos, frente à cerca de $27 \%$ de cobertura na média do Brasil. Neste quesito, a desigualdade inter-regional é muito mais acentuada: enquanto para microrregião de Itapemirim, foi estimada taxa de cobertura efetiva de creche superior a 45\%, na Grande Vitória, pior microrregião evidenciada nesse indicador, a cobertura foi inferior à brasileira, aproximando-se, em 2017, à quase metade da anterior, $24 \%$. 


\section{Gráfico 1 - Taxa de Cobertura Efetiva Pré-escolar por Microrregião, ES e Brasil - 2012 a $2017(\%)$}

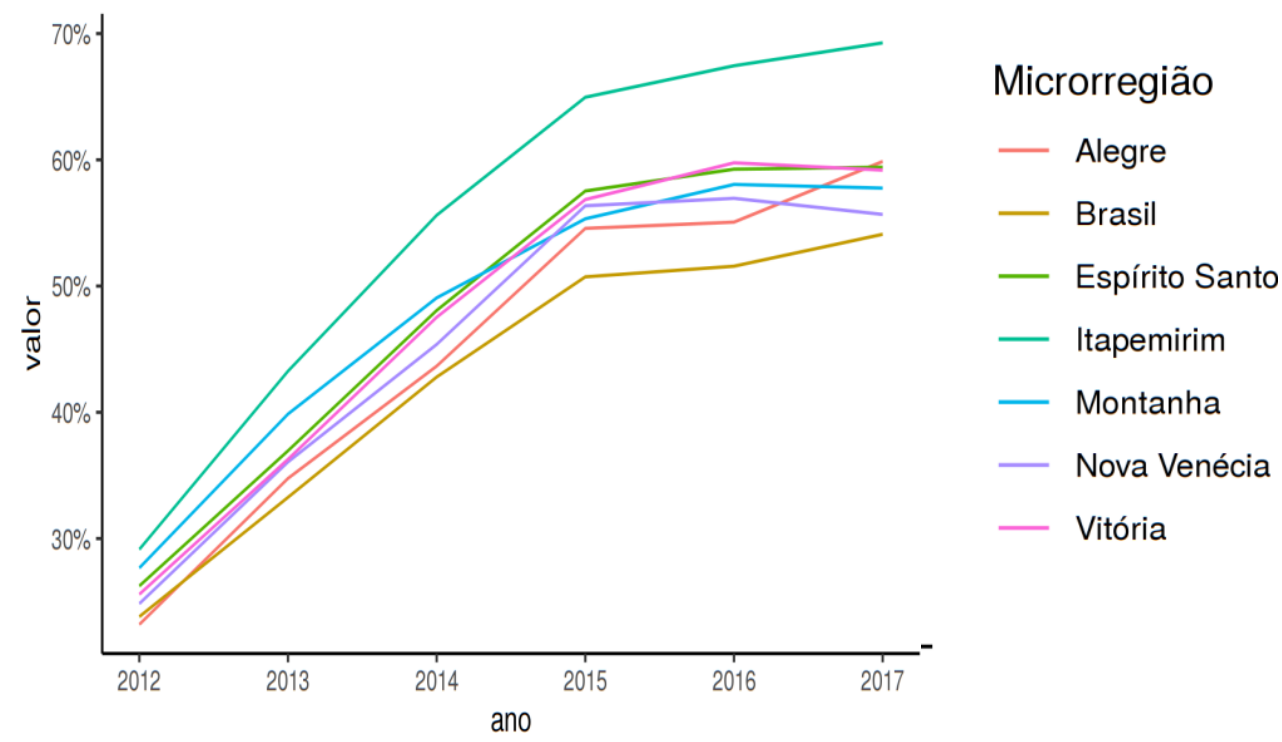

Fonte: Elaboração própria com metodologia exposta e replicável a partir de Borges (2019), com base em microdados do Censo Escolar do INEP-MEC (BRASIL, 2020b), e estimativas atualizadas de população por faixa etária municipal com base em dados de estudo do Ministério da Saúde (BRASIL, 2020c) e IBGE (BRASIL, 2020a).

Sendo considerada, frente ao total de matrículas, a taxa de cobertura em conjunto à de matrículas públicas em pré-escolas, o melhor resultado parece advir da maior oferta destas. Neste indicador, no ES, em todo o período de 2012 a 2017, houve cerca de 88\% de participação de matrículas públicas em relação ao total, enquanto a média brasileira oscilou entre 75 e 77\%.

A região de Vitória, ao concentrar maior população urbana e renda, também apresentou a menor cobertura pública relativa. Já regiões como Nova Venécia e Itapemirim, do ponto de vista das matrículas, possuem um sistema pré-escolar em sua quase totalidade público (acima de 95\%).

Contexto similar, mas com diferenças ainda mais acentuadas, pode ser verificado no que tange às matrículas em creche. No ES, quase $90 \%$ das matrículas nessa etapa são públicas, enquanto, no Brasil, os valores para o mesmo índice são muito inferiores, entre 65 e $67 \%$ no período de análise. Itapemirim e Nova Venécia, novamente, aparecem com grande oferta pública de matrículas, ao lado da região de Alegre. 


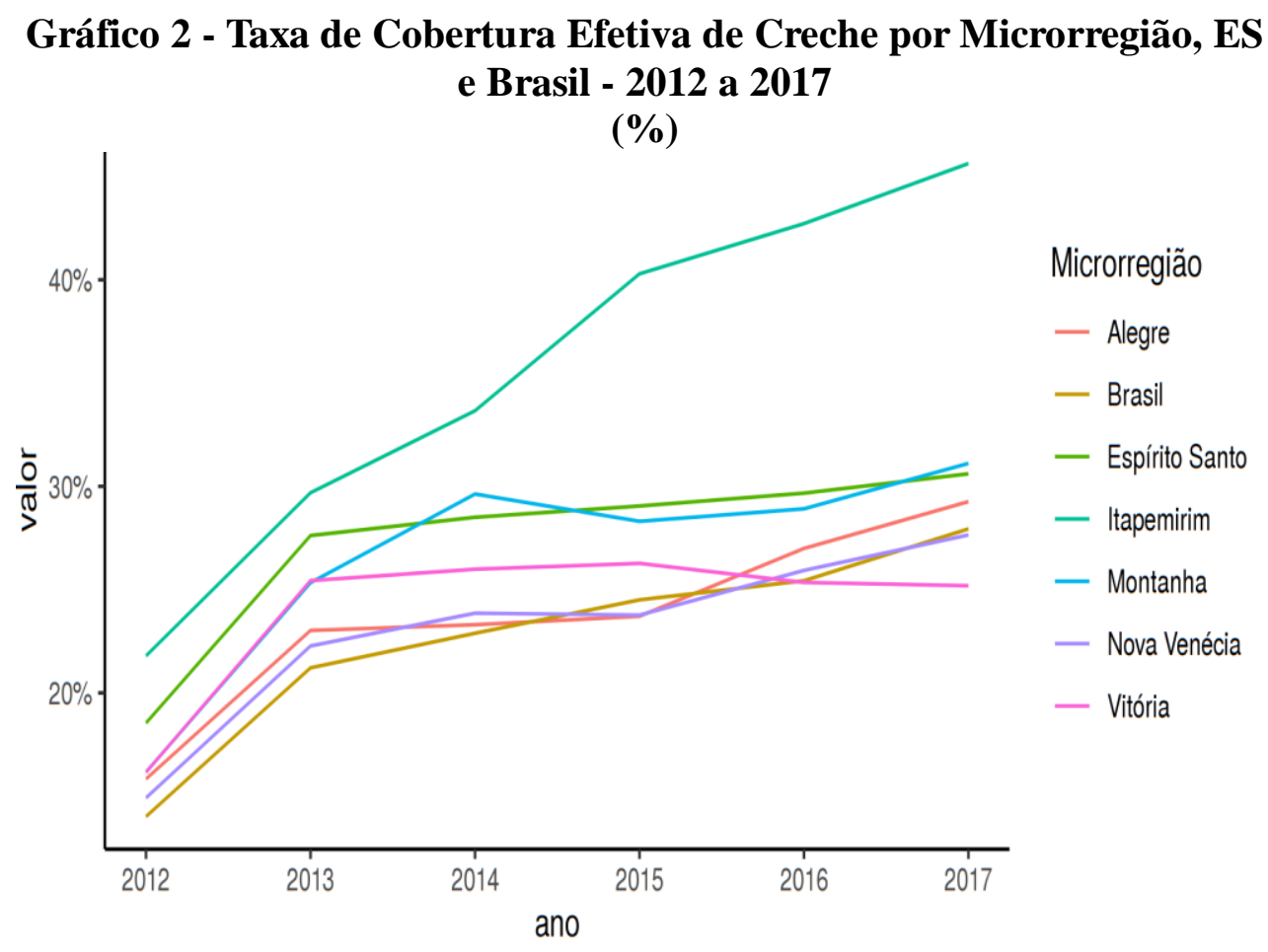

Fonte: Elaboração própria com metodologia exposta e replicável a partir de Borges (2019), com base em microdados do Censo Escolar do INEP-MEC (BRASIL, 2020b), e estimativas atualizadas de população por faixa etária municipal com base em dados de estudo do Ministério da Saúde (BRASIL, 2020c) e IBGE (BRASIL, 2020a).

No tocante à área da saúde, a proporção de partos cesáreos no país é preocupante, superando os $60 \%$. No ES, o cenário é similar, ainda que nos anos recentes tenha se apresentado redução de valores - antes próximos a $68 \%$, e, em 2017 , chegando cerca de $62 \%$ do total de partos. Grande Vitória, dentre as microrregiões selecionadas, aparece como destaque positivo, embora, mesmo destoante nessa dimensão, em 2017, ainda possuísse cerca de 59\% de partos nessa modalidade. Por outro lado, a região de Alegre, no sul do estado, chegou a valores superiores a 70\%, em praticamente todo o período, após 2012, sem nenhum sinal de tendência de declínio.

Quanto à cobertura adequada em assistência pré-natal às gestantes, o panorama é mais homogêneo, mas não demasiado positivo. ES apresenta uma cobertura em termos de gestações com número de consultas pré-natais adequado ou ótimo (mais de 6 consultas), próximo a 69\%, valor em torno do qual boa parte das microrregiões orbita com pequena variação, salvo o caso de Nova Venécia, que apresentou melhora sensivel até alcançar cobertura de mais de 75\%. Itapemirim também se destaca pela forte melhora, reduzindo as fortes divergência e deficiência iniciais nessa cobertura. 


\section{Gráfico 3 - Taxa de Mortalidade Materna - Brasil, Espírito Santo e microrregiões selecionadas - 2012 a 2017}

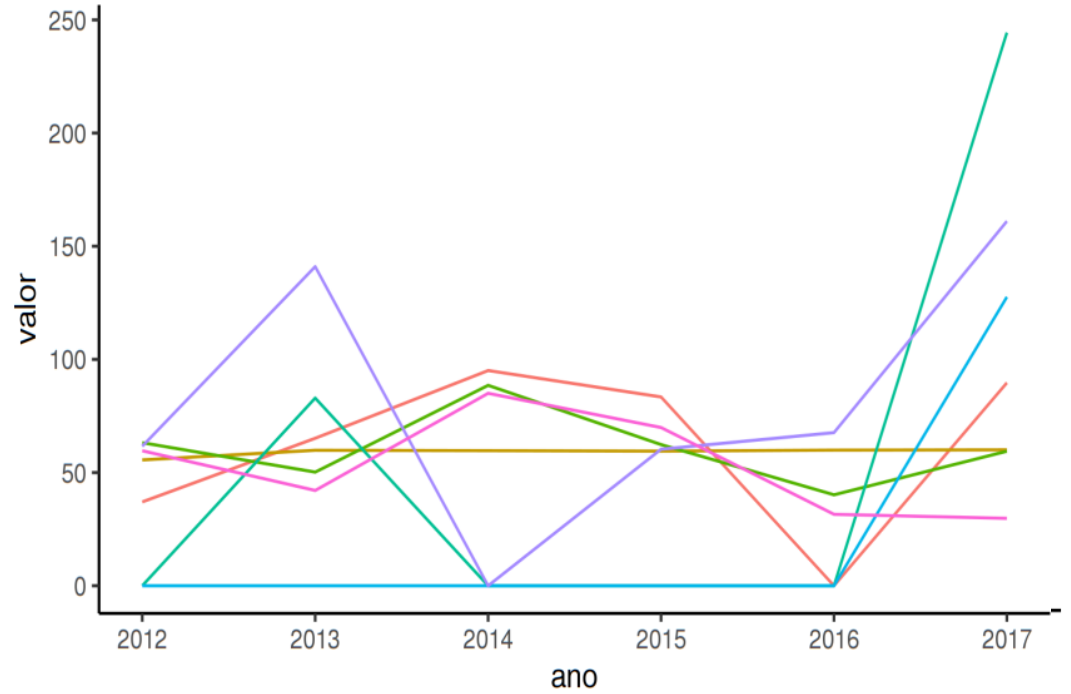

Microrregião

- Alegre

- Brasil

- Espírito Santo

- Itapemirim

- Montanha

- Nova Venécia

- Vitória

Fonte: Elaboração própria com metodologia exposta e replicável a partir de Borges (2019), com base em microdados do DATASUS (BRASIL, 2020d), e estimativas atualizadas de população por faixa etária municipal com base em dados de estudo do Ministério da Saúde (BRASIL, 2020c) e IBGE (BRASIL, 2020a).

A taxa de mortalidade materna () mostrou redução na microrregião de Vitória, partindo de quase 60 mortes por 100 mil nascidos vivos, em 2012, para cerca de 30 em 2017. No período entre 2012 e 2016, as demais microrregiões, ES e Brasil não apresentaram melhora; a taxa de mortalidade materna flutuou, no estado e país, em torno de 60 mortes por 100mil nascimentos. Além disso, nas demais microrregiões selecionadas, é preocupante a evolução registrada entre 2016 e 2017: em todas, nota-se uma elevação significativa, neste último ano, da taxa de mortalidade materna estimada, com valores acima de 90 mortes por 100 mil nascidos vivos.

A taxa de fecundidade adolescente (Gráfico 4) mostrou leve declínio no Brasil e no ES, partindo, respectivamente, de 32 e 28 nascidos por mil adolescentes, na faixa de 15 a 19 anos, em 2012, para 27 e 24, em 2017. A região de Itapemirim apresentou taxa de fecundidade mais elevada, algo em torno de 35, em 2017. A situação estadual espelhou, basicamente, o ocorrido na microrregião de Vitória, cuja redução da taxa de fecundidade adolescente foi de cerca de 29 a 24 por mil nascidos entre 2012 e 2017. À exceção da região de Nova Venécia, entre 2016 e 2017, nota-se uma piora (Itapemirim, Montanha, Alegre), ou redução sensível no ritmo de queda desse indicador (ES, Brasil, Vitória). 


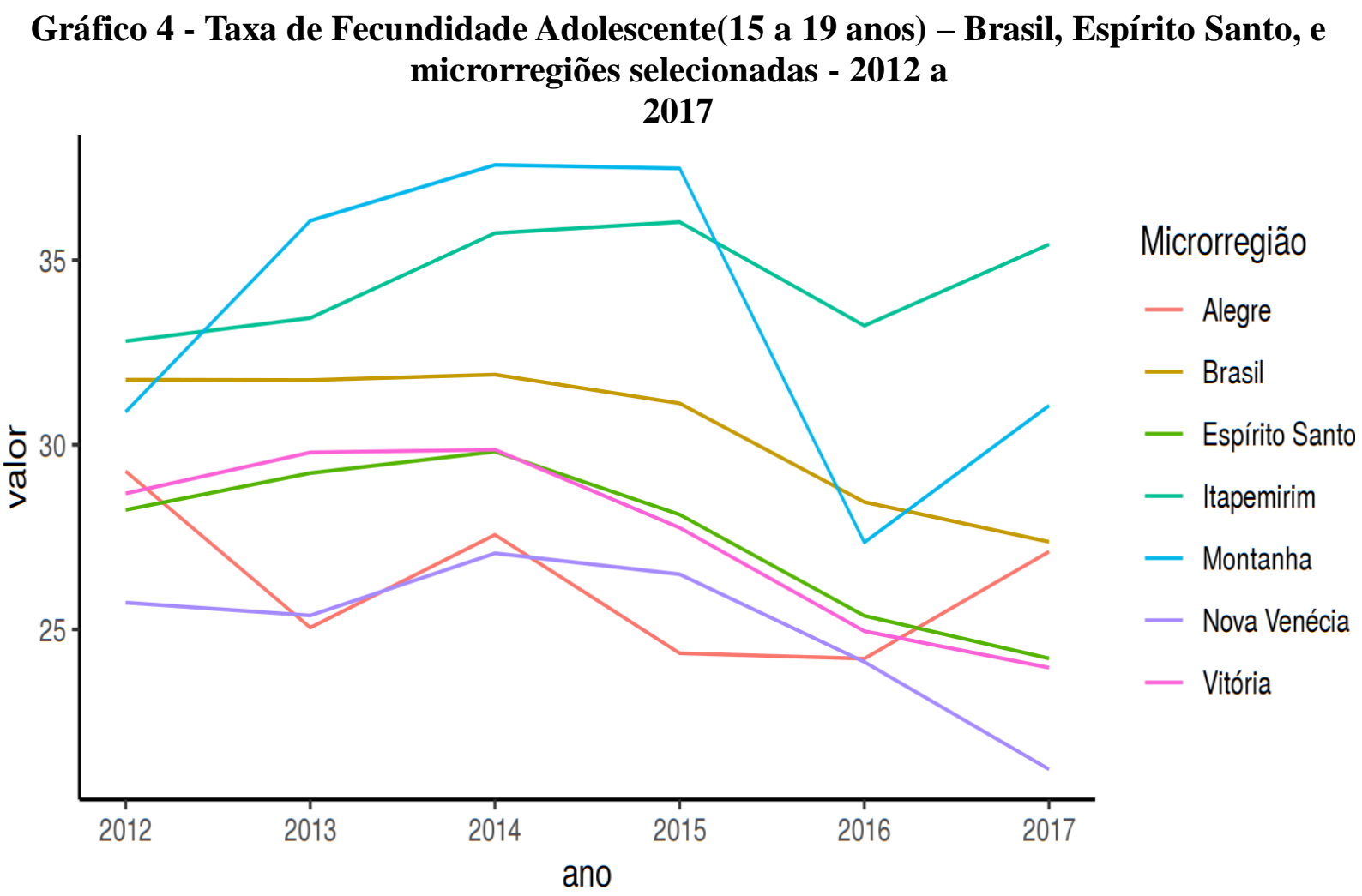

Fonte: Elaboração própria com metodologia exposta e replicável a partir de Borges (2019), com base em microdados do DATASUS (BRASIL, 2020d), e estimativas atualizadas de população por faixa etária municipal com base em dados de estudo do Ministério da Saúde (BRASIL, 2020c) e IBGE (BRASIL, 2020a).

Por fim, os dados extraídos do CadÚnico mostram situação de pobreza na primeira infância bastante mais aguda do que estimam órgãos oficiais de pesquisa. No ES, entre 30\% e 33\% das crianças de 0 a 6 anos estavam cadastradas no CadÚnico, no período de 2012 a 2017, e eram membros de famílias beneficiárias do PBF. Esse volume mostra situações de pobreza e extrema pobreza preocupantes. Na região de Itapemirim, em particular, mais de 50\% dos infantes estimados passaram a ser beneficiados pelo PBF em 2017. Não se verificou tendência à redução da proporção de crianças de 0 a 6 anos beneficiárias do PBF no estado. A partir de 2014, ao mesmo tempo em que se aprofundou a crise econômica, foi possível notar a redução do número absoluto de infantes beneficiários, contrassenso que sugere impactos da austeridade fiscal. 
Figura 1 - Proporção do total de crianças de 0 a 6 anos beneficiárias do Programa Bolsa Família - 2017

$(\%)$

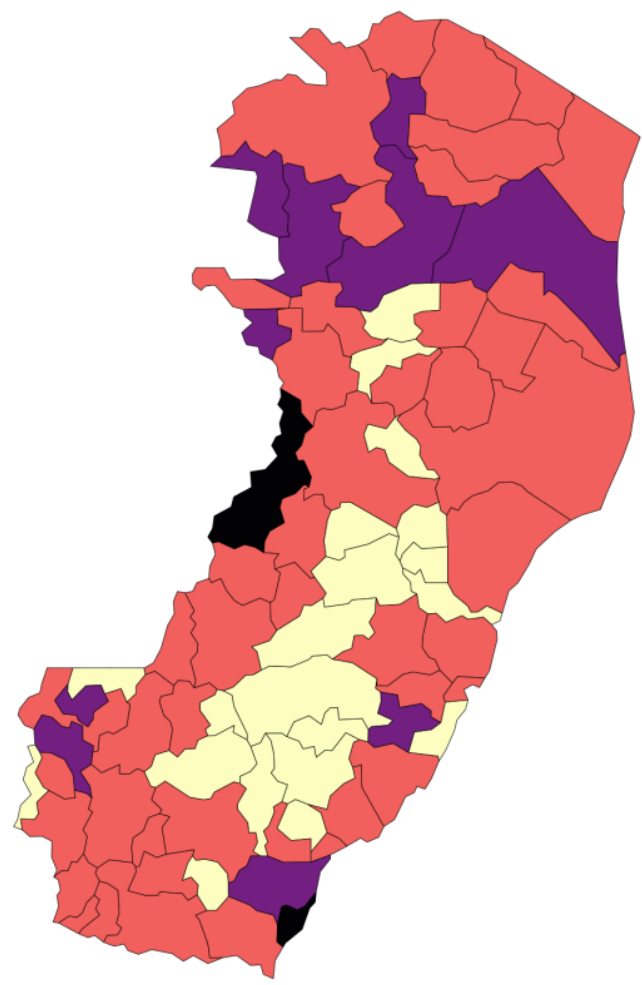
proporção de beneficiárias pbf / pop 0 a 6

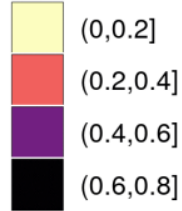

Fonte: Elaboração própria com metodologia exposta e replicavél a partir de Borges (2019), com base em microdados do CADÚNICO (BRASIL, 2020e), e estimativas atualizadas de população por faixa etária municipal com base em dados de estudo do Ministério da Saúde (BRASIL, 2020c) e IBGE (2020).

\section{PERSPECTIVAS E CONSIDERAÇÕES FINAIS}

A análise realizada permitiu visualizar avanços no atendimento à primeira infância no ES. No tocante ao desempenho escolar, em particular, ficou patente como a maior presença do setor público se traduz em melhores cobertura e atendimento às necessidades dos infantes.

A manutenção de disparidades regionais pode ser visualizada em diversos indicadores.

De maneira ainda mais evidente, a partir do desatar da crise econômica brasileira, em 2014, houve um panorama generalizado ou de forte refreamento das tendências de melhora no atendimento das crianças, ou reversão e regressão.

Por fim, nossas estimativas a partir dos microdados do Cadastro Único e estimativas populacionais mostraram uma realidade destoante em relação às análises e discurso oficialista. $A$ pobreza entre crianças não foi reduzida no período de 2012 a 2017, no ES, e representa proporção significativa quanto ao total de infantes capixabas, de mais de $30 \%$, conforme indicado. 


\section{REFERÊNCIAS}

ADELANTADO, J. Reestructuración de los Estados del Bienestar ¿Hacia un cambio de paradigma? Revista Argumentum, v.9, n. 2, p. 38-52, 2017. Disponível em:

http://www.periodicos.ufes.br/?journal=argumentum\&page=article\&op=view\&path\%5B\%5D=16163. Acesso em: 1 dez. 2019.

ASSOCIAÇÃO NACIONAL DE PETRÓLEO. Superintendência de Desenvolvimento e Produção.

Boletim da Produção de Petróleo e Gás Natural, n. 101, 28 fev. 2019. Disponível em:

http://www.anp.gov.br/images/publicacoes/boletins-anp/Boletim_Mensal-

Producao_Petroleo_Gas_Natural/boletim-janeiro-2019.pdf. Acesso em: 17 nov. 2019.

AZIZ FILHO, A. Saindo pelo ralo. ISTOÉ, n.1559, 18 ago. 1999. Disponível em:

https://istoe.com.br/33105_SAINDO+PELO+RALO/. Acesso em: 18 agosto 1999.

BARROS, R. P. et al. Pobreza no Espírito Santo. IPEA, Brasília, n. 1476, mar. 2010. Disponível em http://www.ipea.gov.br/portal/images/stories/PDFs/Tds/td_1476.pdf. Acesso em: 10 nov. 2019.

BITTENCOURT, G. A formação económica do Espírito Santo: o roteiro da industrialização: do engenho as grandes indústrias (1535-1980). Vitória: Departamento Estadual de Cultura do Estado do Espírito Santo, 1987.

BORGES, R. E. S. Microdados de Política Social (scripts para o software R). 2019. Disponível em: https://github.com/rodrigoesborges/microdadosbrasilpoliticasocial/

BRASIL. Objetivos do Milénio: Relatório Nacional de Acompanhamento. Brasília: Ipea, 2010.

Disponivel em: http://www.ipea.gov.br/portal/images/stories/PDFs/100408_relatorioodm.pdf. Acesso em: 10 nov. 2019.

BRASIL, Instituto Brasileiro de Geografia e Estatística. Estimativas da população. 2020a. Disponível em: https://www.ibge.gov.br/estatisticas/sociais/populacao/9103-estimativas-de-

populacao.html?=\&t=downloads . Acesso em: 3 jan. 2020.

BRASIL, Instituto Nacional de Estudos e Pesquisas Educacionais Anísio Teixeira. Microdados do Censo Escolar da Educação Básica. Vários anos. 2020b. Disponível em: http://portal.inep.gov.br/web/guest/censo-escolar . Acesso em: 17 jan. 2020.

BRASIL, Ministério da Saúde. Estudo de estimativas populacionais por município, idade e sexo 2000-2015 - Brasil. 2020c. Disponível

em: http://tabnet.datasus.gov.br/cgi/deftohtm.exe?novapop/cnv/popbr.def. Acesso em: 3 jan. 2020.

BRASIL, Ministério da Saúde. Informações de Saúde(TABNET). DATASUS - Departamento de Informática do SUS. 2020d.

Disponível em: http://www2.datasus.gov.br/DATASUS/index.php?area=02 . Acesso em: 17 jan. 2020.

BRASIL. Secretaria Especial de Desenvolvimento Social. Microdados desidentificados do

CadÚnico. 2020e. Disponível em: https://aplicacoes.mds.gov.br/sagi/portal/index.php?grupo=212 .

Acesso em: 15 jan. 2020. 
CARVALHO, AI. Determinantes sociais, económicos e ambientais da saúde. In: FUNDACĀO OSWALDO CRUZ. A saúde no Brasil em 2030 - prospecção estratégica do sistema de saúde brasileiro: populacão e perfil sanitário [online]. Rio de Janeiro: Fiocruz/lpea/Ministério da Saúde/Secretaria de Assuntos Estratégicos da Presidencia da República, v. 2. p. 19-38, 2013.

CECCON, C. As crianças são o Brasil: elas não podem esperar. In: CÂMARA DOS DEPUTADOS. Primeira infância: avanços do marco legal da primeira infância. Brasília: Centro de estudos e debates estratégicos. Cadernos de trabalhos e debates, Brasília, n. 11, p. 24-59, 2016. Disponível em: https://www2.camara.leg.br/a-camara/estruturaadm/altosestudos/pdf/obra-avancos-do-marco-legal-daprimeira-infancia. Acesso em: 01 dez. 2019.

DARÉ, R. A. "crise" do café e a ideologia desenvolvimentista no Espírito Santo. 2010, $203 \mathrm{f}$. Dissertação (Mestrado em Geografia) - Centro de Ciência Humanas e Naturais, Universidade Federal do Espírito Santo (UFES), Vitória, 2010.

ESPING-ANDERSEN, G; PALIER, B. Los tres grandes retos del Estado del bienestar. 1 ed. Barcelona: Ariel, 2010.

ESPÍRITO SANTO. Plano de Desenvolvimento 2025. Vitória (ES): Secretaria de Estado de Economia e Planejamento, 2006. Disponível em: https://sesp.es.gov.br/Media/sesp/Plano\%20ES\%202025/Plano\%20de\%20Desenvolvimento\%20ES\%2 02025.pdf. Acesso em: 10 nov. 2019.

ESPÍRITO SANTO. ES2030 Plano de Desenvolvimento. Vitória, 2013. Disponível em: https://planejamento.es.gov.br/Media/sep/Plano\%20ES\%202030/ES2030.pdf. Acesso em: 30 nov. 2019.

ESPÍRITO SANTO. Comissão de elaboração e acompanhamento do Plano estadual de Educação. Diagnóstico da Educação no estado do Espírito Santo. 2014. Disponível: http://portal.sedu.es.gov.br:83/PDFs/DIAGNOSTICO.pdf. Acesso em: 17 nov. 2019.

FERRARI, T. K. et al. Avaliação de impacto ex-ante de uma política de transferéncia de renda no Espírito Santo. Vitória: Instituto Jones dos Santos Neves, 2011.

FUJIMOTO, G. Cenário mundial das políticas de primeira infância. In: CÂMARA DOS DEPUTADOS. Primeira infância: avanços do marco legal da primeira infância. Brasília: Centro de estudos e debates estratégicos. Cadernos de trabalhos e debates, Brasília, n. 11, p. 24-59, 2016. Disponível em: https://www2.camara.leg.br/a-camara/estruturaadm/altosestudos/pdf/obra-avancos-do-marco-legal-daprimeira-infancia. Acesso em: 1 dez 2019.

FOLHA ONLINE. Entenda a crise no Espírito Santo, chamado de "Estado sem lei". Folha de São Paulo, São Paulo, 24 mar. 2003, Cotidiano. Disponível em: http://www1.folha.uol.com.br/folha/cotidiano/ult95u71738.shtml. Acesso em: 10 nov. 2019.

GARCIA, M.T.; GARCIA, M.L.T. O Vale do do Itabapoana e a História de São Pedro do Itabapoana e São José do Calçado. Vitória: EDUFES, 1997.

GOMES, $H$. Potenciais e limites às políticas regionais de desenvolvimento no estado do Espírito Santo - o apego às formas tradicionais de Intermediação de interesses. Dissertação (Mestrado), Universidade Federal do Espírito Santo (UFES), Vitória, 1998. 
GOMES, E. C F. Desconcentração produtiva regional no Brasil: o estado do Espírito Santo (1990 a 2005). 2008. Dissertação (Mestrado em Desenvolvimento Econômico) - Programa de Pós-graduação em Desenvolvimento Econômico, Universidade Estadual de Campinas, São Paulo, Campinas, 2008.

GOMES, H. A crise econômica e os efeitos distributivos da austeridade seletiva proposta pela atual gestão de Paulo Hartung. Vitória: Sindipúblicos - Sindicato dos trabalhadores e servidores públicos do estado do Espírito Santo, 2015 (mimeo).

IBGE, INSTITUTO BRASILEIRO DE GEOGRAFÍA E ESTATÍSTICA. Pesquisa Nacional por Amostra de Domicílios: Síntese de Indicadores. Brasília, 2009. Disponível em:

https://biblioteca.ibge.gov.br/visualizacao/livros/liv45767.pdf.Acesso em: 10 nov. 2019

IJSN, INSTITUTO JONES DOS SANTOS NEVES. Primeira infância: análise do marco legal e a situação no Espírito Santo. Vitória: IJSN. 2016. Disponível em:

http://www.ijsn.es.gov.br/ConteudoDigital/20161014_ij01428_td56_prineirainfancia_.pdf. Acesso em: 20 nov. 2019.

MACHADO, R. A. Pedido de intervenção federal no Espírito Santo. Brasília: OAB. 14 maio 2002. Disponivel em: https://www.oab.org.br/noticia/723/veja-integra-do-pedido-de-intervencao-no-es-feitopela-oab. Acesso em: 29 nov. 2019.

MAGALHÃES, M. A. de; TOSCANO, V.N. Hierarquia urbana e polarização populacional: um estudo a partir de cidades do Espírito Santo. In: FERRARI, M.A.R.; ARTHMAR, R. Novas leituras sobre a economia do Espírito Santo. Vitória: PPGEco/CORECON-ES, v. 1, p. 121-146, 2011.

OLIVEIRA, J. T. História do estado do Espírito Santo. Vitória: Arquivo Público do estado do Espírito Santo: Secretaria de Estado da Cultura, 2008

OLIVEIRA JR. R. B. As políticas educacionais do segundo mandato do governo Paulo Hartung e seus impactos no trabalho docente. 2013.148 f. Dissertação (Programa de Pós-Graduação em Educação) Centro de Educação da Universidade Federal do Espírito Santo. Vitória. 2013. Disponível em: < http://repositorio.ufes.br/bitstream/10/6080/1/Ruy\%20Barboza\%20de\%200liveira\%20Junior.pdf>. Acesso em: 15 nov. 2019.

OLIVEIRA, U. J.; LIRIO, M. M. Projeto Escola Viva: a política de educação neoliberal de Paulo Hartung, no Espírito Santo (2003-2016). CLio - Revista de Pesquisa Histórica, v. 35, n.1, p. 273-295, 2017. Disponível em: https://periodicos.ufpe.br/revistas/revistaclio/article/view/25043/20283. Acesso em: 15 nov. 2019.

PEREIRA, S. M.; SAMPAIO, A. P. S. Políticas Sociais para a primeira infância: contexto e perspectivas. Vitória: Instituto Jones dos Santos Neves, 2011.

ROCHA, H. C.; MORANDI, A. M. Cafeicultura e grande indústria: a transição no Espírito Santo 19551985. 2 ed. Vitória: Espírito Santo em Ação, 2012.

SIQUEIRA, M. P. S. Industrialização e empobrecimento urbano: o caso da Grande Vitória (19501980). Vitória: Edufes, 2001.

SIQUEIRA, M. P. S. A questão regional e a dinâmica econômica do Espírito Santo - 1950/1990. 
POLÍTICA SOCIAL E DESENVOLVIMENTO DA PRIMEIRA INFÂNCIA: mapeando condições no Espírito Santo, 2012 a

Revista de História e estudos culturais, v. 6, n. 4, p. 1-16, 2009. Disponível em: http://www.revistafenix.pro.br/ZIP21/ARTIGO_10_Maria_da_Penha_Smarzaro_Siqueira.zip.

\section{Notas}

1 Esses fatos receberam ampla cobertura dos principais meios de comunicação do país e foram amplamente noticiados, como é possivel verificar em diversas reportagens, cf. Aziz Filho (1999) e Folha Online (2003).

2 Para aprofundar na motivação que embasou a intervenção federal no estado, cf. Machado (2002).

3 "[...] definiu-se como sendo pobres, para o estado do Espírito Santo, aqueles que recebem uma renda domiciliar per capita abaixo de $\mathrm{R} \$ 157,56$ na área urbana e abaixo de $\mathrm{R} \$ 134,47$ na área rural; já os extremamente pobres são aqueles com renda domiciliar per capita inferior a $R \$ 78,78$ na área urbana e de até $R \$ 67,24$ na área rural" (FERRARI et al, 2011, p. 8).

4 "As afecç̃oes perinatais incluem os transtornos relacionados com a curta duração da gestação, os problemas cardiorrespiratórios do recém-nascido e os traumatismos de parto, entre outras causas" (BRASIL, 2010, p. 77).

${ }^{5}$ Constituição Federal (1988), Estatuto da Criança e do Adolescente (1990) e Lei de Diretrizes e Bases da Educação (1996).

6 Verificou-se para o caso do Espírito Santo que todas as crianças cadastradas no CadÚnico faziam parte de famílias beneficiadas pelo PBF.

7 Em Borges (2019), é possível obter e consultar a metodologia detalhada, comentada e replicável, utilizando o software livre $R$.

${ }^{8}$ As quatro mesorregiões capixabas, na classificação do IBGE, são: Noroeste, Litoral Norte, Centro e Sul. 